\title{
The Influence of Collaborative Learning in Creating Rhythmic Ensemble Music
}

\author{
Diah Latifah*, Henry Virgan \\ Universitas Pendidikan Indonesia \\ Bandung, Indonesia \\ *diahlatifah@upi.edu, henryvirgan@upi.edu
}

\begin{abstract}
The research examines the advantages of collaborative learning for creating ensemble rhythmic music. The primary objective was to scan the collaborative learning process in the creative process of creating rhythmic ensembles. The research method used is a quasi-experimental, ex post facto study, comparing the learning outcomes of rhythmic music creation before using collaborative learning and after using collaborative learning, involving 28 students. The results reveal that collaborative learning had a positive effect on the creation of rhythmic music ensembles, measured using the Wilcoxon Signed Ranks Test. The comparison results indicate that there is a significant difference before and after the treatment (sig $=0.000$ $<0.05)$. In fact, there is a significant increase from an average number of 40.0 prior to the treatment to 80.71 following the treatment.
\end{abstract}

Keywords - collaborative learning, creating rhythmic, ensemble music

\section{INTRODUCTION}

Current music learning studies require an analysis that anticipates the communication aspects of playing music ensembles. The present study concentrates on social and communicative aspects emerging when knowledge is articulated among the ensemble members, either 'verbally' or through 'action' [1].

Ensemble music has a prominent role to play in the world of music, not only because it has collaborative value, but this type of music also allows students to understand various musical genres. Ensemble playing is considered central in different genres in specialist higher music education, not least because of its collaborative nature [1].

Collaborative learning is one of the $21^{\text {st }}$-century skill goals. Here is how teaching the Three Artistic Processes model helps students master the headline 21st-century skills in the partnership map, the so-called four Cs: Creativity, Critical Thinking, Communication, and Collaboration [2]. Collaborative learning of ensemble music which is carried out in Indonesia today is still to achieve music skills that belong together. According to collaborative learning experts Keith Topping and Stewart Ehly, peer-assisted learning - an instructional arrangement where peers help each other to gain knowledge and skill through active help and support - entails individuals sharing knowledge until it becomes a common possession [3]. Learning collaborative ensemble music utilizing old fashioned learning is not directed at achieving musical creativity in accordance with the direction of the skills of the $21^{\text {st }}$ century. In order to achieve the demands of one of the goals of craftsmanship in the $21^{\text {st }}$ century, namely creativity, in the form of rhythmic music creation this study was carried out.

\section{A. Ensemble Music}

Ensemble music is a form of music that has the characteristic of playing music together, or in groups, either in one kind or in a mixture. Randel stated "a group of performers who perform together, whether instrumentalists, singers, or some combination, e.g., a string ensemble, an early-music ensemble" [4]. A music ensemble performance is defined as a music show that is played consciously by a group of musicians. Kokotsaki stated "Here, musical performance will be defined as one 'in which a performer, or a group of performers, selfconsciously engages music for an audience" [5].

\section{B. Collaborative Learning and Music Composing in Ensemble Music}

Learning music ensembles requires the participation of each member, "in participatory music a piece is more like a set of resources, like the rules and stock moves of a game, refashioned anew during each performance" [6]. Turino notes: I am using the idea of participation in the restricted sense of actively contributing to the sound and motion of a musical event through dancing, singing, clapping, and playing musical instruments when each of these activities is considered integral to the performance [6]. Collaborative learning in the creative process of a music ensemble is an activity of collective participation in a work of creation. Collaborative music creativity has advantages in problem-solving, through communication among its members. Collaborative creativity refers to the distribution of creativity across members of a group as they collaborate to solve a shared problem [7]. Learning music with the process of creating and arranging music has a priority, to achieve the current goals of music education that link creativity with collaboration. The report calls for a radical transformation of college music education 
more resonant with participatory music, stating that "improvisation and composition provide a stronger basis for educating musicians today than the prevailing model of training performers in the interpretation of older works" [6]. The research explores the connections between creativity and collaboration within a genre-specific ensemble [8]. The main focus of our research study is that the music ensemble performed by the participants is a rhythmic ensemble, which uses a body instrument and tools or objects around the research participants, in this case composing music in an a-tonal concept. Feldman's ideal: "a totally abstract sonic adventure," in which the aim was "to project sounds into time, free from compositional rhetoric" [9]. The creation of a-tonal music uses rhythmic music composition, because Ilari stated "Rhythmic entrainment is at the core of collective music-making" [10].

\section{METHODS}

The research method used is a quasi-experiment, which compares preliminary data before treatment (ex post facto data), in the form of student learning outcomes before using collaborative learning for musical creativity in the form of a music ensemble. Data after treatment is data on student learning outcomes.

The research sample consisted of 28 students, who had proven to have a sense of rhythm. Rhythmic talent is obtained from the rhythm taste test by school music teachers, through imitation tests of various rhythm patterns of Indonesian national songs, in binary and ternary bars. Divided into two groups, each group comprised 14 people.

Indicators of achievement from the creativity of rhythmic music produced by students are:

- Students have the ability to make Deletion rhythmic motifs in music ensemble sentences.

- Students have the ability to make Embellishment rhythmic motifs in music ensemble sentences.

- Students have the ability to create Augmentation rhythmic motifs in music ensemble sentences.

- Students have the ability to make Diminution rhythmic motifs in music ensemble sentences.

These four rhythmic motifs are explored to be used as elements of composing musical compositions.

Samples were analyzed parametrically using the Wilcoxon comparison test, in the form of comparing samples before treatment and after treatment. The form of music activities carried out is in the form of reciprocating activities with rhythmic motives in the form of question and answer activities, by:

One group made an initial rhythmic motif, the other responded with a rhythmic motif according to the four indicators.
Each group created the initial rhythmic motif, and then responded by another group. As a result, each group had the opportunity to create initial motives, and develop four motives according to the indicators.

This quasi-experimental test was carried out at one of the high schools in Bandung West Java Indonesia, from May to August 2018.

The pre-test is a test made by school teachers (ex post facto data) that already exists and becomes a data bank for teacher evaluation results in the previous semester. The post-test is the result of the use of collaborative learning in the creation of a rhythmic music ensemble as part of a collaboration between the researchers and the school music teacher.

\section{A. Data Collected}

The research sample of the initial value before treatment (pre-test) was collected by taking the rhythmic accuracy value of last semester, in the form of a rhythmic imitation test result of the national song by means of evaluating clapping to play a melody rhythmic pattern and moving the leg movements according to the bar.

The research sample of post-treatment results test scores was collected by taking collaborative work test scores, creating initial rhythmic motives, and developing four rhythmic motifs according to the indicators.

\section{RESULTS}

\section{A. Data Description}

The pre-test is the ex post facto score data, in the form of test results made by the teacher from last semester.

The post-test is a test that develops rhythmic motives collaboratively according to indicators. The test result is a score.

Test scores before and after treatment were compared using the Wilcoxon Signed Ranks Test (Table 1).

TABLE I. WILCOXON SIGNED RANKS TEST

\begin{tabular}{|c|l|l|l|l|}
\hline \multicolumn{2}{|c|}{} & \multicolumn{1}{|c|}{$\begin{array}{c}\text { N } \\
\text { Mean of } \\
\text { Rank }\end{array}$} & $\begin{array}{c}\text { Sum of } \\
\text { Ranks }\end{array}$ \\
\hline \multirow{3}{*}{$\begin{array}{c}\text { Posttest - } \\
\text { Pretest }\end{array}$} & Negative Ranks & $0^{\mathrm{a}}$ & .00 & .00 \\
\cline { 2 - 5 } & Positive Ranks & $23^{\mathrm{b}}$ & 12.00 & 276.00 \\
\cline { 2 - 5 } & Ties & $5^{\mathrm{c}}$ & & \\
\cline { 2 - 5 } & Total & 28 & & \\
\hline
\end{tabular}

TABLE II. REPORT

\begin{tabular}{|c|l|l|}
\hline & \multicolumn{1}{|c|}{ Pretest } & \multicolumn{1}{c|}{ Posttest } \\
\hline Mean & 40,0000 & 80,7143 \\
\hline Std. Deviation & 22,11083 & 20,07921 \\
\hline Median & 45,0000 & 85,0000 \\
\hline Minimum & 20,00 & 45,00 \\
\hline Maximum & 85,00 & 100,00 \\
\hline
\end{tabular}


The report table (Table 2) is the average number, standard deviation, median value, lowest value and highest value before and after treatment.

The comparison using the Wilcoxon Signed Ranks Test as results show that there is a significant difference between before and after the treatment $(\mathrm{sig}=0.000<0.05)$. In fact, there is a significant increase from before being treated with an average number of 40.0 to 80.71 after the treatment was performed.

The calculation results show that the score of collaborative rhythmic music creativity treatment is greater than the score before the treatment, and this means, Posttest> Pretest. The increase in the score after treatment (post-test) compared to before treatment (pre-test) can be seen in figure 1 .

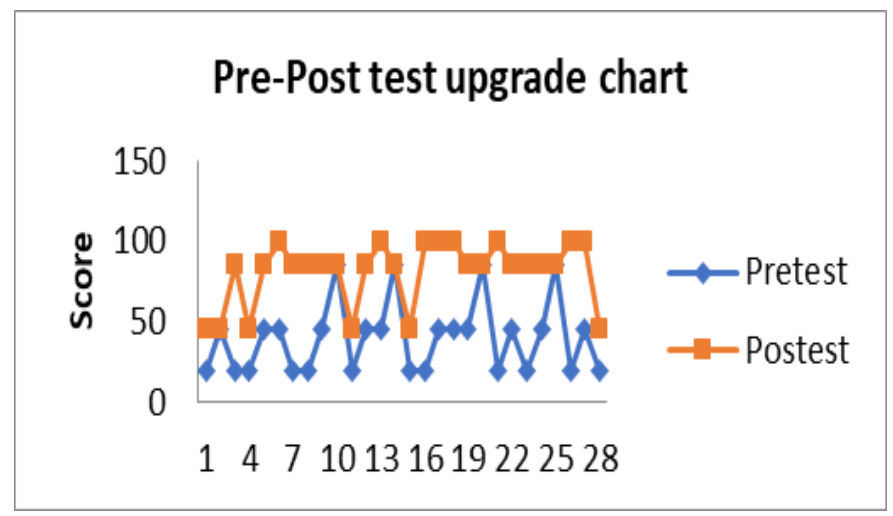

Fig. 1. Graph of the increase in the score after treatment (post-test) compared to before treatment (pre-test).

\section{DISCUSSION}

The findings from Wilcoxon's calculations suggest that learning music ensembles that are played collaboratively have the advantage of increasing the ability to create rhythmic music sentences, in the form of ensemble music. When students play music collaboratively, they exchange ideas with communication to create rhythm patterns (a combination of several motifs) which are used as rhythmic music melody works. Likewise, when they respond to rhythmic patterns created by other groups, they communicate to create rhythm patterns in response to the rhythm patterns they receive from the opposing group. The group started creating rhythmic music with 14 members completed by another group or 14 other people who created rhythmic music as a response pattern according to the indicator, to compose a complete melody sentence. Such collaborative work has the potential to foster 'creative collaboration' where both the 'complementarity' and the 'tensions' within groups help create the right conditions for creativity to occur [8].

\section{CONCLUSION}

The results of this study indicate that collaborating in the creation of music creation is an integral aspect that can be interpreted as theoretical support for music learning. Kenny affirmed Characterizing creativity as a group process resonates 'collective action' is an integral part of any arts collective [8]. This happens because the communication process in collaborative work is multi-directional, which results in many ideas to be identified and combined into a musical work.

\section{ACKNOWLEDGMENT}

This research was supported by the 2018 research funds from Research Grant from the Ministry of Research, Technology and Higher Education of the Republic of Indonesia

\section{REFERENCES}

[1] A.L. Slette, "Negotiating Musical Problem-solving in Ensemble Rehearsals," British Journal of Music Education, vol. 36, no. 1, pp. 1-15, 2019

[2] S.C. Shuler, "Music Education for Life: The Three Artistic Processes: Paths to Lifelong 21st-Century Skills through Music," Music Educators Journal, vol. 97, no. 9, 2011

[3] E. Johnson, "Peer-teaching in the Secondary Music Ensemble," Journal of Education and Training Studies, vol. 3, no. 5, pp. 35-42, 2015

[4] D.M. Randel, "The New Harvard Dictionary of Music," Cambridge: The Belknap Press of Harvard University Press, 1986.

[5] D. Kokotsaki, "Understanding the Ensemble Pianist: A Theoretical Framework," Psychology of Music, vol. 35, no. 4, pp. 641-668, 2007

[6] M.D. Thibeault, "Music Education for All through Participatory Ensembles.," Music Educators Journal, vol. 103, no. 2, pp. 54-61, 2015.

[7] L. Bishop, "Collaborative Musical Creativity: How Ensembles Coordinate Spontaneity," Frontiers in Psychology, vol. 9, p. 1285, 2018.

[8] A. Kenny, "Collaborative Creativity within a Jazz Ensemble as Musical and Social Practice," Thinking Skill and Creativity, vol. 13, pp. 1-8, 2014.

[9] T. Orning, "Music as Performance - Gestures, Sound and Energy," Journal for Research in Arts and Sports Education, vol. 1, pp. 79-94, 2017

[10] B. Ilari, "Rhythmic Engagement with Music in Early Childhood: A Replication and Extension," Journal of Research in Music Education, vol. 62 , no. 4, pp. 332-343, 2015. 